12,03

\title{
Влияние облучения на свойства коллоидных наночастиц сульфида серебра $\left(\mathrm{Ag}_{2} \mathrm{~S}\right)$
}

\author{
(C) С.В. Ремпель ${ }^{1,2}$, Ю.В. Кузнецова ${ }^{1}$, Е.Ю. Герасимов ${ }^{3}$, А.А. Ремпель ${ }^{1,2}$ \\ ${ }^{1}$ Институт химии твердого тела УрО РАН, \\ Екатеринбург, Россия \\ ${ }^{2}$ Уральский фредеральный университет им. Б.Н. Ельцина, \\ Екатеринбург, Россия \\ ${ }^{3}$ Институт катализа СО РАН, \\ Новосибирск, Россия \\ E-mail: svetlana_rempel@ihim.uran.ru
}

(Поступила в Редакцию 20 декабря 2016 г.)

\begin{abstract}
Исследованы водные растворы, содержащие наночастицы сульфида серебра $\left(\mathrm{Ag}_{2} \mathrm{~S}\right)$, из разных областей стабильности. Стабильный прозрачный и мутный растворы выдерживались при дневном свете в течение семи месяцев, подвергались воздействию ультрафиолетового и лазерного излучения, а также электронного пучка. Облучение солнечным светом приводит к восстановлению $\mathrm{Ag}_{2} \mathrm{~S}$ в растворе до $\mathrm{Ag}$ и/или образованию гибридных наночастиц $\mathrm{Ag}_{2} \mathrm{~S} / \mathrm{Ag}$. При существенной концентрации гибридных наночастиц экситон-плазмонное взаимодействие приводит к появлению асимметрии в спектрах поглощения. Воздействие электронным пучком на осажденные из раствора частицы $\mathrm{Ag}_{2} \mathrm{~S}$ ведет к обратимому росту нитей $\mathrm{Ag}$. Рассмотрены возможные механизмы экситон-плазмонного взаимодействия в гибридной наночастице $\mathrm{Ag}_{2} \mathrm{~S} / \mathrm{Ag}$. Физическими механизмами изменения стехиометрии $\mathrm{Ag}_{2} \mathrm{~S}$, образования металлического $\mathrm{Ag}$, формирования гибридных наночастиц $\mathrm{Ag}_{2} \mathrm{~S} / \mathrm{Ag}$ являются генерация горячих носителей и перенос энергии (экситон-плазмонное взаимодействие) в гибридной наносистеме металл-полупроводник.
\end{abstract}

Исследование выполнено в ИХТТ УрО РАН за счет гранта Российского научного фонда (проект № 14-23-00025).

DOI: $10.21883 /$ FTT.2017.08.44765.452

\section{1. Введение}

В настоящее время большое внимание уделяется изучению гибридных наноструктур, состоящих из полупроводниковых и металлических наночастиц, благодаря их уникальным свойствам [1-6]. Для успешного применения таких гибридных структур необходимо детальное изучение процессов их формирования. Много работ посвящено исследованию генерации и транспорта горячих носителей, передачи энергии и связанных с этими явлениями оптических, магнитных, фотопроводящих, каталитических свойств гетероструктур металл/полупроводник [7-12]. Одним из объектов, интересных с точки зрения модельного изучения и практического применения, является $\mathrm{Ag}_{2} \mathrm{~S}$ в наносостоянии благодаря его склонности к нестехиометрии $\left(\mathrm{Ag}_{2-x} \mathrm{~S}\right)$. Подвижность ионов $\mathrm{Ag}^{+}$в $\mathrm{Ag}_{2} \mathrm{~S}$ способствует формированию различных гибридных структур $\left(\mathrm{Ag}_{2} \mathrm{~S}-\mathrm{CdS}-\mathrm{ZnS}\right.$, $\left.\mathrm{AgInS}_{2}-\mathrm{Ag}_{2} \mathrm{~S}-\mathrm{AgInS}_{2}, \mathrm{Ag}_{2} \mathrm{~S}-\mathrm{ZnS}-\mathrm{CdS}-\mathrm{ZnS}\right)$ в зависимости от внешних условий и сопутствующих компонентов [13]. Воздействие излучения и приложенного электрического напряжения может приводить как к изменению стехиометрии $\operatorname{Ag}_{2} \mathrm{~S}$, так и к образованию наночастиц серебра. Так, под воздействием приложенного к образцам $\mathrm{Ag}_{2} \mathrm{~S}$ напряжения, происходила протрузия $\mathrm{Ag}$ на поверхности $\mathrm{Ag}_{2} \mathrm{~S}$ [14]. Воздействуя элек- тронным пучком, удавалось изменять соотношение $x / y$ в $\left(\mathrm{Ag}_{2} \mathrm{~S}\right)_{x}(\mathrm{Ag})_{y}[15]$. Изменение устойчивости коллоидных растворов золота и серебра под действием видимого света и ультрафиолетового (UV) излучения наблюдали ранее авторы работ $[16,17]$, в которых также обнаружено, что скорость коагуляции зависит от длины волны и мощности излучения.

Целью настоящей работы является изучение процессов, происходящих при старении образцов коллоидных растворов, содержащих наночастицы $\mathrm{Ag}_{2} \mathrm{~S}$, с течением времени и при воздействии облучения.

\section{2. Методы и материалы}

Синтез коллоидных растворов наночастиц $\mathrm{Ag}_{2} \mathrm{~S}$ проводился по методике, описанной в [18]. В качестве источников ионов серебра и серы для синтеза наночастиц методом химической конденсации были выбраны водные растворы нитрата серебра $\mathrm{AgNO}_{3}$ и сульфида натрия $\mathrm{Na}_{2} \mathrm{~S}$, соответственно. Для предотвращения коагуляции частиц в растворе и достижения долговременной агрегативной устойчивости в качестве комплексующего и стабилизирующего агента использовался цитрат натрия $\mathrm{Na}_{3} \mathrm{C}_{6} \mathrm{H}_{5} \mathrm{O}_{7}$. В результате предварительных экспериментов по синтезу коллоидного раствоpa, содержащего наночастицы $\mathrm{Ag}_{2} \mathrm{~S}$, в зависимости от 
Изменение размеров наночастиц $\mathrm{Ag}_{2} \mathrm{~S}$ в растворе после синтеза, до и после облучения

\begin{tabular}{c|c|c|c|c}
\hline \multirow{2}{*}{ Образец } & \multirow{2}{*}{ Свойство } & \multicolumn{3}{|c}{ Среднее значение $D_{h}$ наночастиц, $\mathrm{nm}$} \\
\cline { 3 - 5 } & & $\begin{array}{c}\text { после } \\
\text { синтеза }\end{array}$ & до облучения & $\begin{array}{c}\text { после облучения } \\
\mathrm{UV}(15 \mathrm{~min})\end{array}$ \\
\hline Раствор I & Стабильный & 8 & 3 & 5 \\
Раствор II & Мутный & 17 & 12 & 19
\end{tabular}

соотношения исходных компонентов были определены область стабильности, в которой при данных значениях концентраций исходных реагентов растворы остаются стабильными и прозрачными в течение длительного времени, и область мутности, которая определяет получение непрозрачных растворов с образованием небольшого количества осадка в некоторых случаях [19]. Для исследования влияния облучения на растворы, содержащие коллоидные наночастицы $\mathrm{Ag}_{2} \mathrm{~S}$, были выбраны два образца: из области стабильности (раствор I) и области мутности (раствор II) соответственно.

Измерение гидродинамического диаметра $D_{h}$ наночастиц $\mathrm{Ag}_{2} \mathrm{~S}$ непосредственно в коллоидном растворе проведено методом динамического рассеяния света (DLS) на приборе Zetasizer Nano ZS (Malvern Instruments Ltd.). Измерения проводились методом обратного рассеяния под углом $173^{\circ}$ с использованием гелий-неонового лазера $(633 \mathrm{~nm})$ при температуре $25^{\circ} \mathrm{C}$. Данный прибор также позволяет измерять дзета-потенциал $\xi$ наночастиц в растворе, являющийся показателем стабильности системы [20-24].

Мутность контролировалась турбидиметром НI 93703 MICROPROCESSOR TURBIDITY METER, шкала которого изменяется от 0 до 100 , а нулю соответствует мутность дистиллированной воды.

Аттестация образцов методом оптической спектроскопии проводилась в UV-, видимой и ближней инфракрасной областях спектра от 190 до $2300 \mathrm{~nm}$ при комнатной температуре с помощью спектрофлуориметра FS5 (Edinburgh Instruments) и двухлучевого спектрофотометpa UV-3600 (Shimadzu).

Воздействие электронным пучком на осажденные из коллоидного раствора наночастицы осуществлялось в колонне сканирующего электронного микроскопа в вакууме, ускоряющее напряжение изменялось от 5 до $30 \mathrm{kV}$, расстояние до образца 4.1 и $10.1 \mathrm{~mm}$. Источником UV-излучения была ртутная лампа HB0 103/W2 в совокупности с полосным фильтром 325-420 nm. Время воздействия составляло 5, 15 и $30 \mathrm{~min}$.

Химический анализ методом энергодисперсионной рентгеновской спектроскопии (EDX) и изучение морфологии образцов расслоившегося раствора проводились методом сканирующей электронной микроскопии (SEM) на микросопе JSM JEOL 6390LA. Морфология наночастиц из раствора изучалась на микроскопе FEI NANOLAB 600, EDX-анализ полученных наночастиц проводился на микроскопе FEI QUANTA.

\section{3. Результаты эксперимента}

Гидродинамический диаметр, определяемый методом DSL, представляет собой размер рассеивающих центров, состоящих из наночастиц $\mathrm{Ag}_{2} \mathrm{~S}$, стабилизирующей органической оболочки цитрата и сольватной оболочки из молекул дисперсионной среды. Анализ результатов DLS в течение первого дня после синтеза показал, что система наночастиц в водном растворе является динамической, и для достижения определенного равновесия требуется около суток. В течение месяца размер наночастиц устанавливается наименьшим и остается неизменным более полугода (рис. 1). Дзета-потенциал наночастиц $\mathrm{Ag}_{2} \mathrm{~S}$ в водном растворе отрицателен, что подтверждает образование стабилизирующей цитратной оболочки. Цитрат-ионы по отношению к поверхности частиц обладают помимо электростатического еще и адсорбционным потенциалом, что при избытке цитрата может приводить не только к уменьшению дзета-потенциала, но и к изменению его знака. Такая специфическая адсорбция связана с поляризуемостью данного иона или с поляризацией ионов/молекул на поверхности [25].

В таблице представлены значения размеров наночастиц $\mathrm{Ag}_{2} \mathrm{~S}$ в растворе после синтеза, до и после облучения.

В результате воздействия UV-излучения происходит увеличение среднего значения $D_{h}$ наночастиц и в ста-

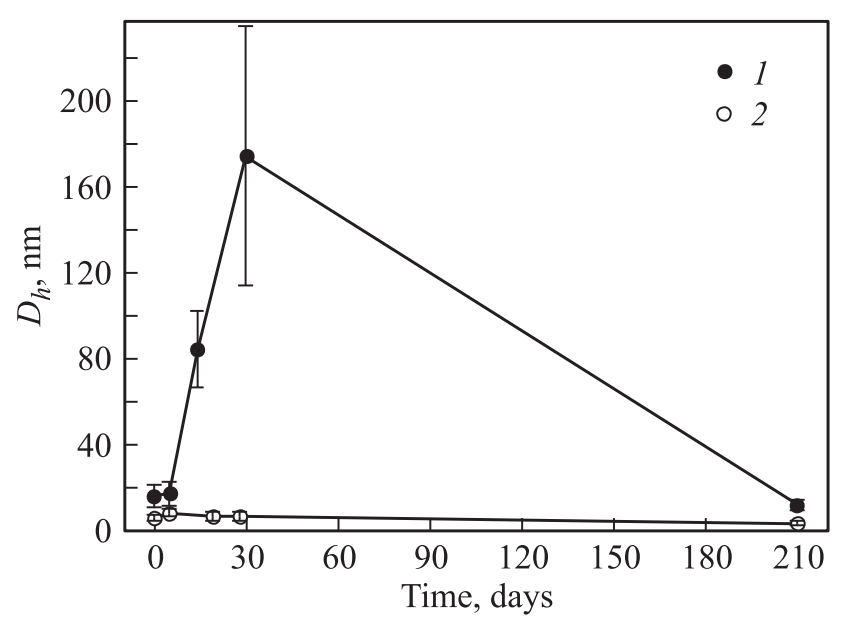

Рис. 1. Изменение среднего гидродинамического диаметра $D_{h}$ наночастиц $\mathrm{Ag}_{2} \mathrm{~S}$ в стабильном коллоидном растворе I (2) и мутном растворе II $(1)$ со временем. 


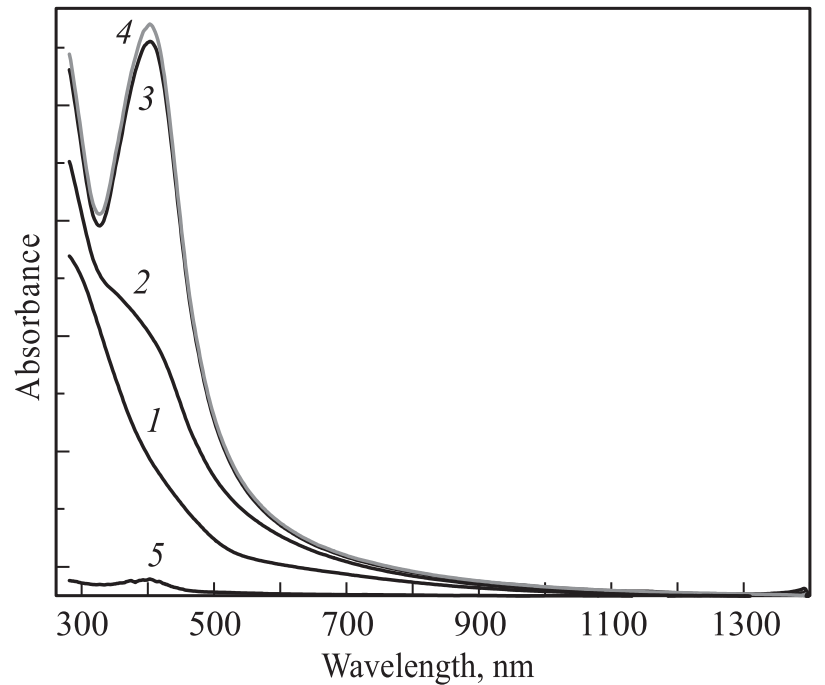

Pис. 2. Спектры оптического поглощения стабильного коллоидного раствора I, содержащего наночастицы $\mathrm{Ag}_{2} \mathrm{~S} .1$ - после синтеза, 2 - через шесть месяцев после синтеза, 3 перед облучением (семь месяцев после синтеза), 4 - после облучения UV-излучения в течение $15 \mathrm{~min}, 5-$ разность спектров, полученных до и после облучения.

бильном (I), и в мутном (II) растворах. Однако в случае раствора I дзета-потенциал по модулю возрастает, что свидетельствует об увеличении стабильности системы. В растворе II дзета-потенциал по модулю уменьшается, нестабильность системы подтверждается образованием осадка.

В процессе измерений размера методом DLS при воздействии на раствор гелий-неоновым лазером $(633 \mathrm{~nm}$, максимальная выходная мощность до $4 \mathrm{~mW}$ ) в течение 3 hв было отмечено образование пятна с металлическим блеском на стенке кюветы в месте прохождения лазерного луча с диаметром, соответствующим диаметру луча, что может свидетельствовать о процессе восстановления серебра на стенке кюветы под действием лазерного излучения.

После синтеза спектр оптического поглощения стабильного раствора представлял собой типичный спектр коллоидного раствора, содержащего наночастицы сульфида серебра (кривая 1 на рис. 2) [26,27]. Через шесть месяцев хранения на свету раствора I в спектре оптического поглощения появилась ступенька (кривая 2 на рис. 2). В соответствии с [28] поглощение света коллоидным раствором, в котором находятся металлические и полупроводниковые наночастицы, определяется суммой поглощений этих наночастиц.

Положение ступеньки в спектре (кривая 2 на рис. 2) совпадает с положением плазмонного пика наночастиц $\mathrm{Ag}$ (типичный спектр коллоидного раствора наночастиц серебра представлен в работах $[3,7])$; следовательно, можно сделать вывод, что ступенька связана с появлением в растворе наночастиц Ag. В течение следующего месяца количество восстановленного серебра увеличилось, и в спектр оптического поглощения основной вклад вносит поглощение наночастиц серебра. Положение максимума поглощения $402 \mathrm{~nm}$ определяется окружающей средой и адсорбированными ионами [7].

После облучения UV-излучением поглощение в области плазмонного пика наночастиц Ag несколько увеличилось. Увеличение поглощения после облучения может быть объяснено увеличением количества и/или размера наночастиц $\mathrm{Ag}$ в растворе. Из литературы [29] известно, что с ростом размера наночастиц и отклонением формы от сферической происходит сдвиг плазмонного пика в красную область спектра. Отсутствие сдвига максимума плазмонного пика после облучения в область больших длин волн может свидетельствовать о незначительном увеличении размера наночастиц (незначительном увеличении количества $\mathrm{Ag}$, восстановленного на поверхности $\mathrm{Ag}_{2} \mathrm{~S}$ ) при данных условиях и сохранении формы, близкой к сферической, поскольку чем больше аспектное отношение, тем больше сдвиг.

Механизм роста наночастиц Ag в присутствии цитрата при облучении (фотовольтажный механизм) описан в работе [30]. Возбуждение поверхностных плазмонов в $\mathrm{Ag}$ ведет к необратимому окислению адсорбированных цитратных анионов. Цитрат выделяет $\mathrm{CO}_{2}$ после переноса электрона к „горячей“ дырке наночастицы серебра. В результате этого процесса наночастица приобретает отрицательный заряд. Если в растворе присутствуют ионы $\mathrm{Ag}^{+}$, то за счет кулоновского взаимодействия происходит притяжение ионов к поверхности наночастиц $\mathrm{Ag}$ и их рост. Плазмон-индуцированный рост прямо пропорционально зависит от энергии падающего света, причем частицы могут расти до так называемого светоконтролируемого размера в зависимости от длины волны падающего света [31].

Рост наночастиц $\mathrm{Ag}$ на поверхности наночастиц $\mathrm{Ag}_{2} \mathrm{~S}$, т.е. образование гетерочастиц происходит при миграции ионов $\mathrm{Ag}^{+}$к поверхности наночастиц $\mathrm{Ag}_{2} \mathrm{~S}$. Это согласуется с механизмом роста, предложенным в работах $[14,15]$.

С другой стороны, увеличение поглощения света системой при облучении в присутствии металлических наночастиц возможно благодаря плазмонному резонансу. При рассеянии света поверхностными плазмонами металлической наночастицы в дальнюю область возможна абсорбция света другими частицами, которые находятся на расстоянии до сотен нанометров от рассеивающей частицы. При этом увеличивается доля света, поглощенного системой в целом, т.е. восстановление в коллоидном растворе $\mathrm{Ag}$ с образованием металлических наночастиц ведет к возрастанию оптической абсорбции.

Таким образом, в растворе I со временем под действием дневного света и в присутствии цитрата происходит превращение значительной части $\mathrm{Ag}_{2} \mathrm{~S}$ в $\mathrm{Ag}$.

Спектры оптического поглощения мутного раствоpa II, содержащего наночастицы $\mathrm{Ag}_{2} \mathrm{~S}$ спустя семь месяцев хранения на свету и после облучения UV-излу- 


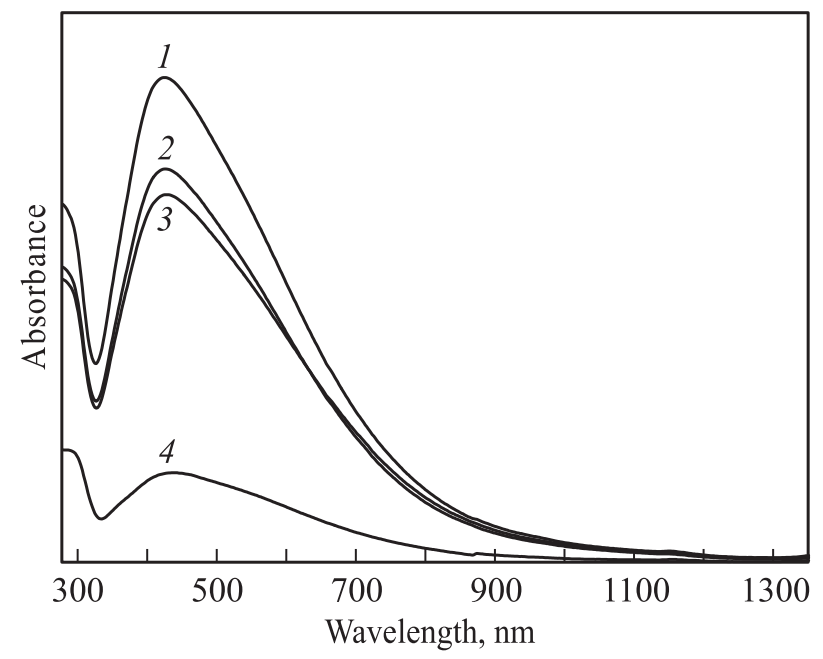

Pис. 3. Спектры оптического поглощения мутного коллоидного раствора II, содержащего наночастицы $\mathrm{Ag}_{2} \mathrm{~S}$, до облучения (1) и после облучения UV-излучения в течение 5 (2), 15 (3) и $30 \min (4)$.

чением в течение различного времени представлены на рис. 3.

Во всех случаях вид спектра одинаков, он представляет собой широкий пик асимметричной формы. С течением времени и в значительной степени после дополнительного облучения интенсивность пика падает. По данным DLS (см. таблицу) с течением времени и под действием UV-излучения в растворе происходит укрупнение частиц с последующим их осаждением. Причиной может являться дипольное взаимодействие, усиленное светом, поглощенным в полосе плазмонного резонанса. В растворе остаются частицы среднего размера около $20 \mathrm{~nm}$. Распределение частиц по размерам после облучения становится монодисперсным. После воздействия UV-облучением в течение $30 \mathrm{~min}$ на дне кюветы появляется очень тонкая пленка розоватого цвета. В исследованиях, проведенных ранее методом просвечивающей электронной микроскопии (ТЕМ), было установлено, что пленки такого цвета соответствовали частицам $\mathrm{Ag}$ диаметром 10-20 nm. Подобное влияние агрегации наночастиц Ag на оптические спектры рассмотрено, в частности, в работе [12]. Максимум пика мутного раствора сдвинут по сравнению с максимумом стабильного раствора в красную область на $24 \mathrm{~nm}$, что соответствует соотношению размеров наночастиц, определенных методом DLS (см. таблицу).

В спектрах поглощения мутного раствора II внимания заслуживает асимметрия пика в области плазмонного резонанса наночастиц серебра. По данным работ $[6,32,33]$ такая асимметрия является следствием резонанса Фано благодаря экситон-плазмонному взаимодействию в металле и полупроводнике. Интенсивность проявления этого эффекта зависит от размеров и взаимного расположения наночастиц полупроводника и ме- талла [27]. При бо́льших энергиях возбуждающего света возможны нелинейный эффект Фано и антирезонансы. При экситон-фононном взаимодействии происходит формирование гибридного экситона со сдвигом экситонной частоты (красный сдвиг) и уменьшением времени жизни. Теоретические и практические исследования [6] показали, что в результате взаимодействия между диполем полупроводниковой наночастицы и металлической наночастицей спектры оптической абсорбции становятся асимметричными и сильно антирезонансными. Эффект взаимодействия может наблюдаться даже при комнатной температуре при малых расстояниях между частицами. С другой стороны, при сильном сцеплении возможно смешивание электронных состояний полупроводника и металла в интерфейсе, что ведет к существенному подавлению плазмонной волны и экситонного возбуждения [5,34]. В исследованном растворе асимметрия пика поглощения свидетельствует о существовании в растворе гибридных наночастиц $\mathrm{Ag}_{2} \mathrm{~S} / \mathrm{Ag}$.

Со временем в растворе II визуально наблюдалось расслоение коллоидного раствора по двум механизмам: на поверхности образовалась тонкая зеркальная пленка серебристого цвета, на дне находился осадок черного цвета. Наличие гетерочастиц с общим интерфейсом в растворах, рассматриваемых в данной работе, показано методом просвечивающей электронной микроскопии высокого разрешения [35]. Принимая во внимание незначительные энергии возбуждающего излучения, случайное расположение металлических и полупроводниковых частиц относительно друг друга можно утверждать, что в нашем случае значительных нелинейных эффектов Фано и антирезонансов ожидать не следует. Взаимодействие проявляется в асимметрии пика, а к понижению интенсивности после облучения могут вести как частичная агрегация частиц (пленка на дне кюветы), так и усиление сцепления в гибридных частицах благодаря восстановлению $\mathrm{Ag}$, приводящее к подавлению резонансного поглощения.

Исходная мутность раствора при малых размерах частиц (см. таблицу) также может являться следствием существования гибридных наночастиц $\mathrm{Ag}_{2} \mathrm{~S} / \mathrm{Ag}$ в раствоpe. В случае системы, включающей близкорасположенные друг к другу металлические и полупроводниковые наночастицы, вследствие резонансов Фано из-за экситонплазмонного взаимодействия может появляться локальная резонансная добавка к коэффициенту поглощения:

$$
\Delta \alpha=A \frac{(\varepsilon+q)^{2}}{\varepsilon^{2}+1}, \quad \varepsilon=\frac{E-E_{\phi}}{\Gamma / 2},
$$

где $E_{\phi}-$ резонансная энергия, $\Gamma-$ ширина резонансного пика. Случайное распределение таких добавок по амплитуде и объему раствора может приводить к эффекту оптической опалесценции, и коллоидный раствор, оставаясь стабильным выглядит мутным.

Пленка с поверхности и осадок со дна были проанализированы методом SEM. В образце с поверхности раствора II (рис. $4, a)$ хорошо видны слипшиеся частицы 

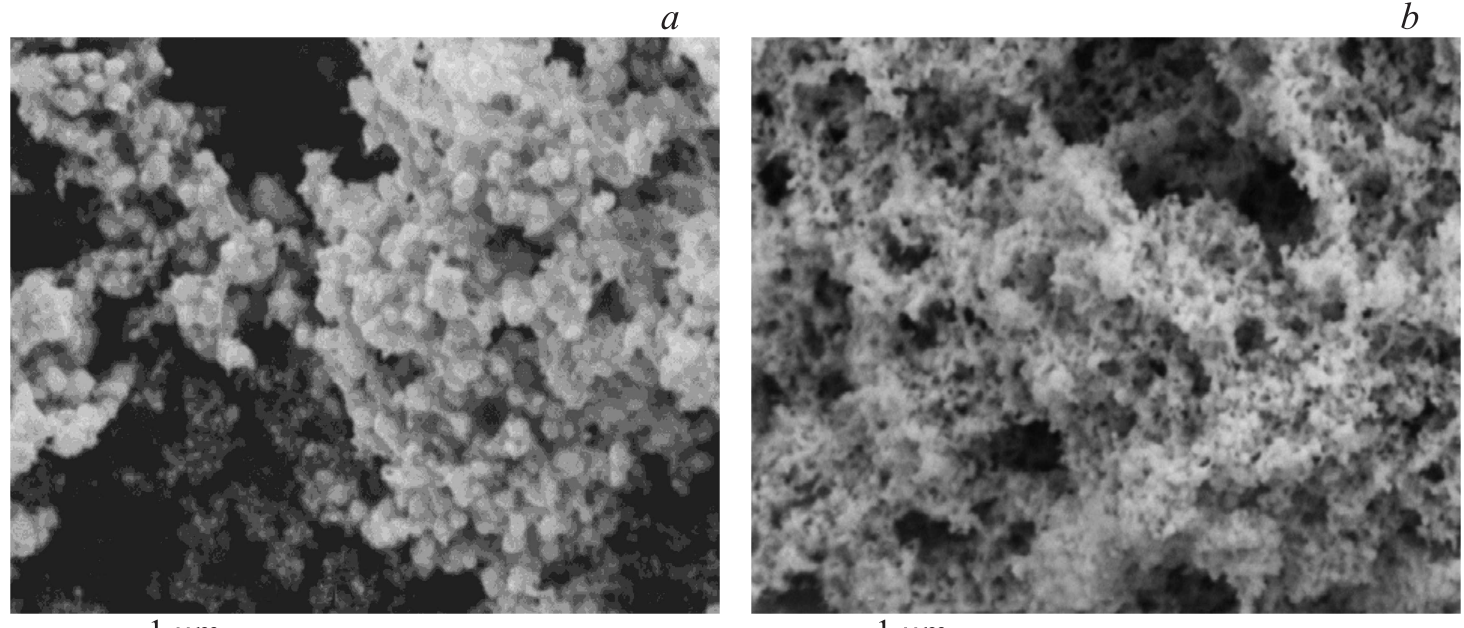

$1 \mu \mathrm{m}$

$-1 \mu \mathrm{m}$

Рис. 4. SEM-изображения пленки, всплывшей на поверхность мутного раствора II $(a)$ и порошка, выпавшего на дно из мутного раствора II $(b)$.

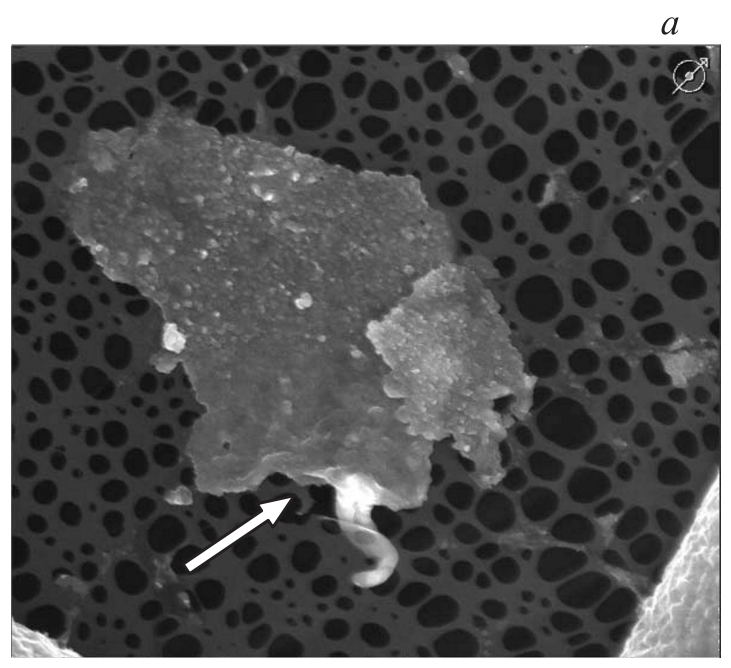

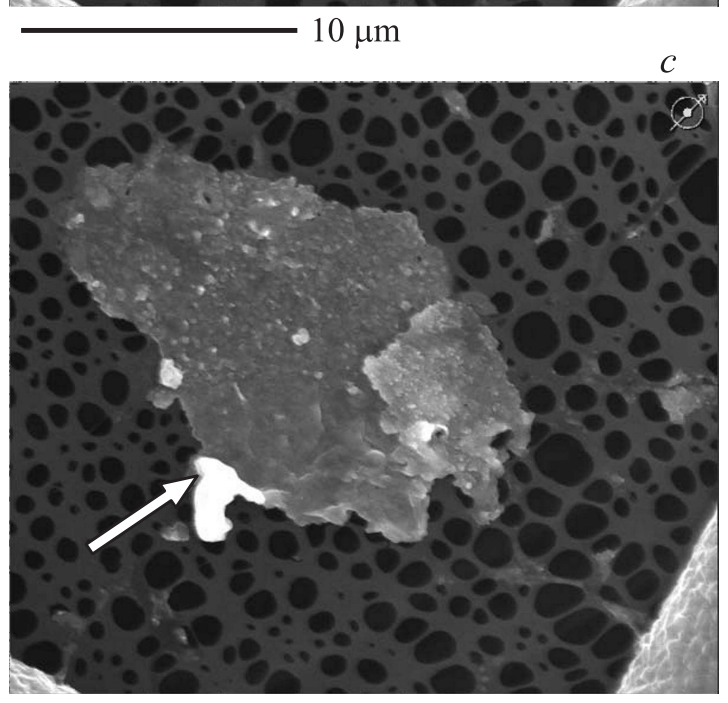

$10 \mu \mathrm{m}$
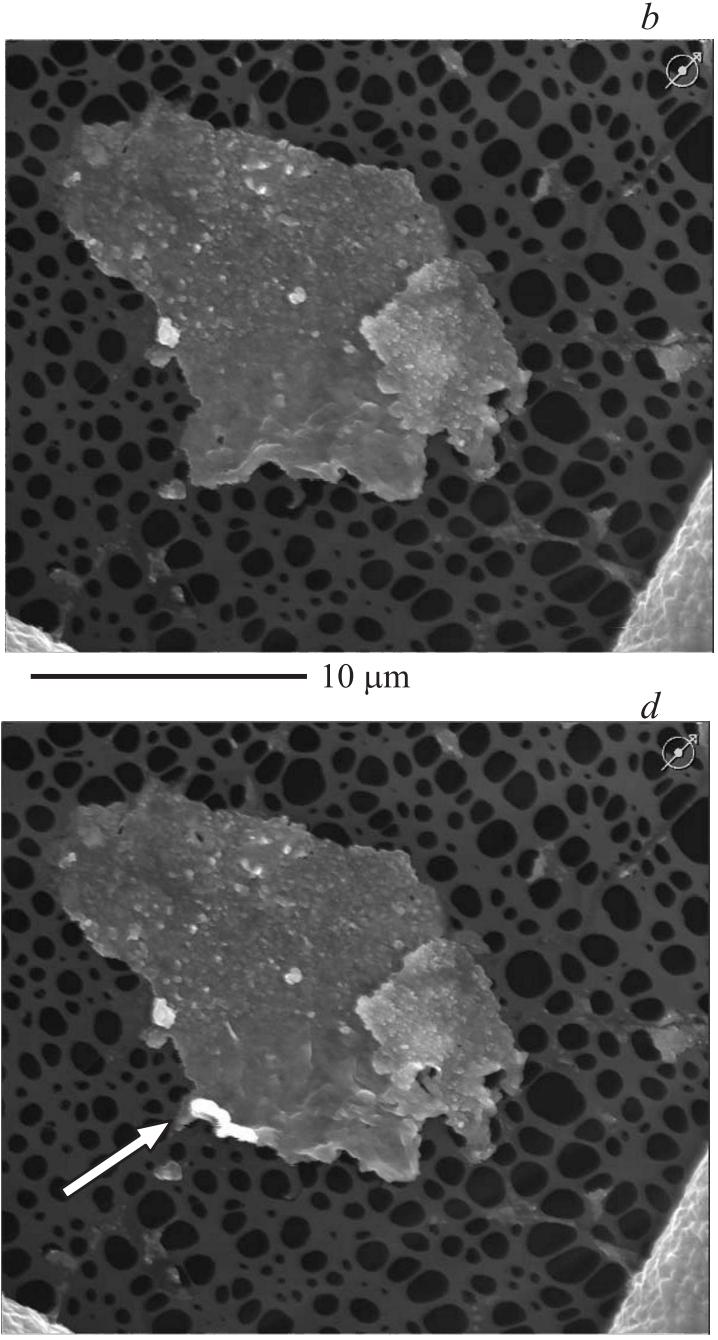

$10 \mu \mathrm{m}$

Рис. 5. Рост нитей $\mathrm{Ag}$ из агломератов наночастиц $\mathrm{Ag}_{2} \mathrm{~S}$ под действием электронного пучка в колонне микроскопа. На частях $a-d$ показана временна́я развертка появления и исчезновения металлического серебра с поверхности агломерата наночастиц $\mathrm{Ag}_{2} \mathrm{~S}$. 


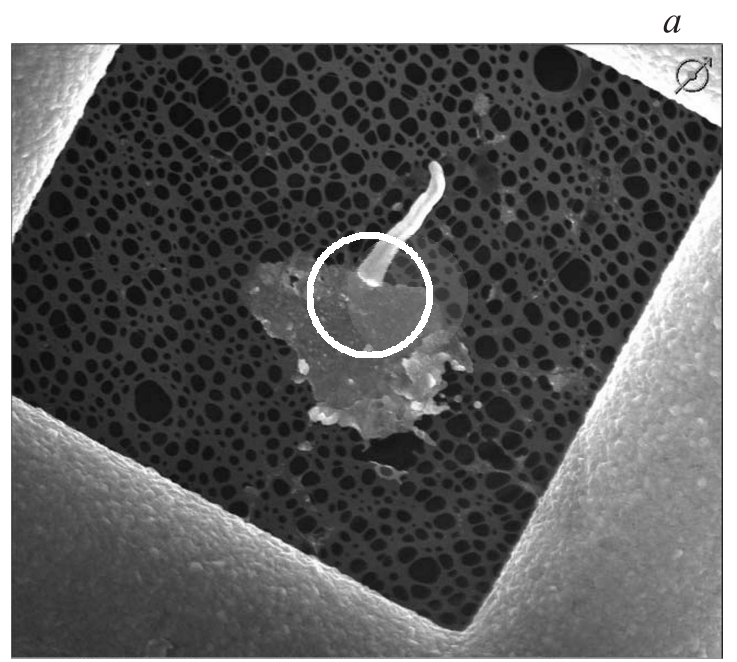

$20 \mu \mathrm{m}$

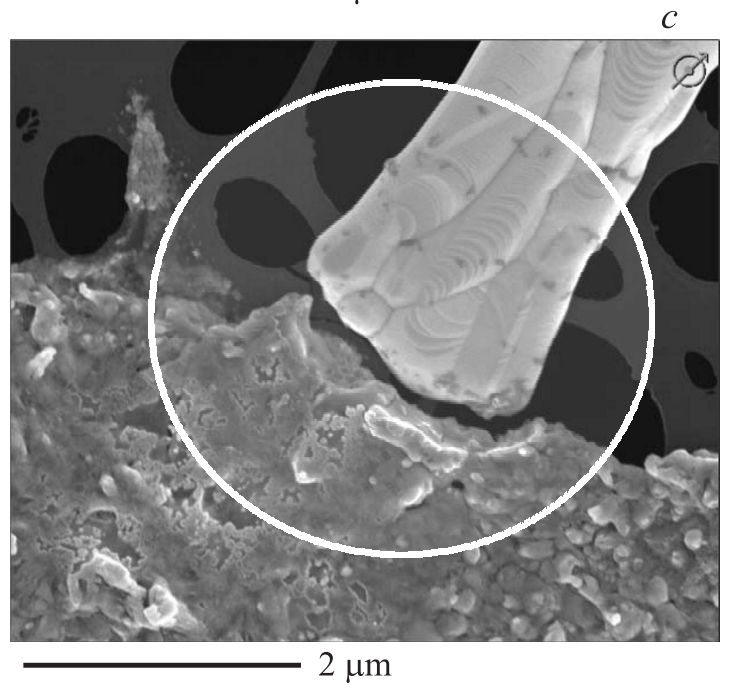

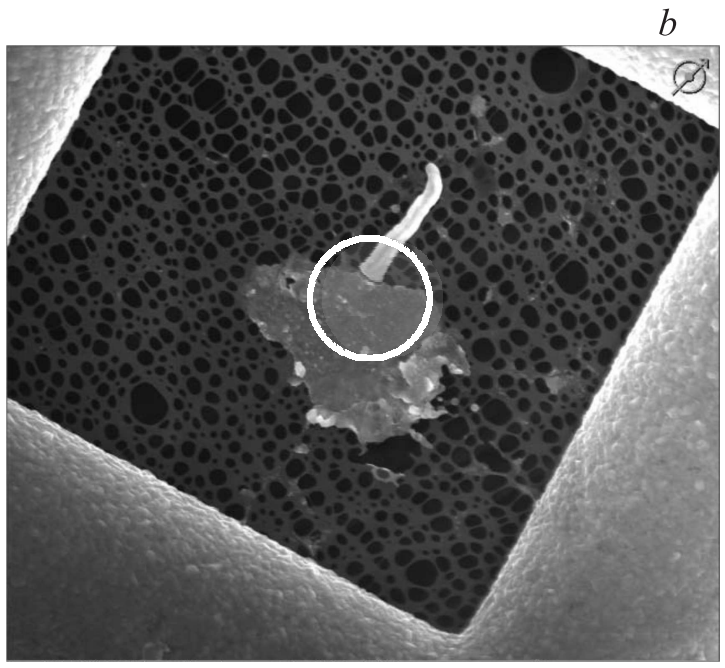

$20 \mu \mathrm{m}$

$d$

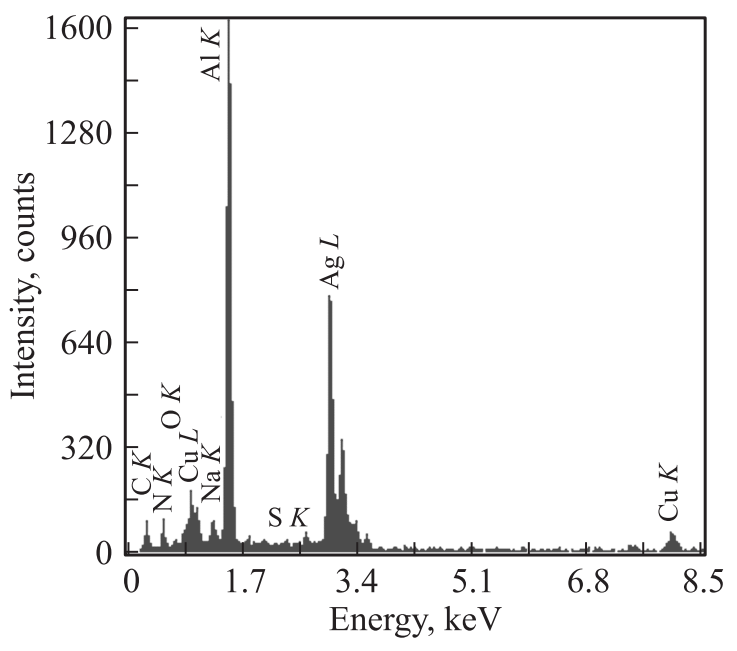

Рис. 6. Рост нити $\mathrm{Ag}$ из агломератов наночастиц $\mathrm{Ag}_{2} \mathrm{~S}$ под действием электронного пучка в колонне микроскопа. $a-$ микро-

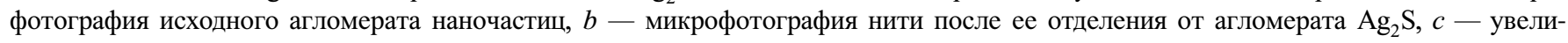
ченное изображение места отделения нити, $d-$ спектр EDX материала нити.

в форме правильных многогранников размером от 100 до $200 \mathrm{~nm}$. По результатам EDX-анализа пленка состоит преимущественно из $\mathrm{Ag}$, в незначительном количестве присутствует S. Частицы из осадка на дне (рис. 4, $b$ ) более мелкие, образуют сетчатую структуру, имеют форму, схожую с частицами с поверхности, и размер до $100 \mathrm{~nm}$. Значительное содержание серы в осадке по сравнению с пленкой на поверхности свидетельствует о преимущественном присутствии в нем $\mathrm{Ag}_{2} \mathrm{~S}$.

Частицы непосредственно из раствора анализировались методом SEM. Для анализа использовалась сеточка для ТЕМ. На рис. 5 представлены микрофотографии агломерата наночастиц, образовавшегося при высыхании растворителя на сеточке. По результатам EDX-анализа агломерат состоял из $\mathrm{Ag}_{2} \mathrm{~S}$. Обнаружено, что при изменении времени сканирования исследуемой области и ускоряющего напряжения от 5 до $30 \mathrm{kV}$ происходит рост нитей на периферии агломерата, а изменение времени сканирования в точке приводит к обратимости этого роста, причем морфология нитей сохраняется. Так, на приведенных снимках показано появление нити $\mathrm{Ag}$ внизу частицы при длительном времени сканирования в данной области (рис. 5, $a$ ), уменьшение интенсивности и увеличение области сканирования приводит к исчезновению частицы $\mathrm{Ag}$ (рис. 5,b) (вероятно ее вхождение обратно в матрицу $\mathrm{Ag}_{2} \mathrm{~S}$ ). Исследование обратимости данного процесса в течение нескольких циклов появления/удаления частицы в области показанной стрелкой на рис. 5,c, приводит к частичной деградации материала, в результате которой часть металлического $\mathrm{Ag}$ уже не встраивается обратно в матрицу $\mathrm{Ag}_{2} \mathrm{~S}$. В результате на рис. 5, $d$ наблюдается некоторое количество $\mathrm{Ag}$ не вошедшее в агломерат $\mathrm{Ag}_{2} \mathrm{~S}$.

Направленное облучение электронным пучком зоны взаимодействия металлического $\mathrm{Ag}$ и $\mathrm{Ag}_{2} \mathrm{~S}$ приводит к отделению выросшей нити от основного материала, 
данный процесс возможен, скорее всего, благодаря резкому изменению температуры и разнице коэффициентов термического расширения. EDX-анализ показал, что выросшие нити состоят из Ag (рис. 6). На основной поверхности агломерата наблюдались зародыши разного размера, поэтому можно предположить, что рост нитей начинается с образования наночастиц $\mathrm{Ag}$, а величина выросших нитей зависит от локальных условий на поверхности образца.

Ранее обратимый рост кластеров серебра (nanowire) на сульфиде серебра наблюдали в работе [14] под действием приложенного напряжения. В нашем случае рост нитей можно объяснить скоплением отрицательного заряда на поверхности полупроводника под действием электронного пучка. При миграции ионов $\mathrm{Ag}^{+}{ }_{\text {в } \mathrm{Ag}_{2} \mathrm{~S}}$ к поверхности создаются условия для протрузии металлического серебра. Не вызывает сомнения тот факт, что важное значение имеют время, величина созданного потенциала (скопившегося заряда), температура поверхности и т.д., которые зависят от характеристик микроскопа. Так, при анализе пленки с поверхности и осадка со дна мутного раствора методом SEM роста нитей $\mathrm{Ag}$ не наблюдалось. Вероятно, в данном случае наличие металлического серебра, случайно распределенного по поверхности образца (осадок мутного раствора), способствует отводу избыточного заряда поверхности, предотвращает создание условий для миграции $\mathrm{Ag}^{+}$к поверхности и протрузии металлического серебра.

\section{4. Обсуждение результатов}

Таким образом, в стабильном растворе I после синтеза формируются наночастицы $\mathrm{Ag}_{2} \mathrm{~S}$. Со временем при хранении на свету происходит образование наночастиц Ag. Воздействие УФ и лазерного излучения ведет к увеличению количества наночастиц $\mathrm{Ag}$ и частично к агломерации (в зависимости от интенсивности и времени облучения).

В мутном растворе II при синтезе формируются наночастицы трех типов: $\mathrm{Ag}_{2} \mathrm{~S}, \mathrm{Ag}$ и гибридные наночастицы $\mathrm{Ag}_{2} \mathrm{~S} / \mathrm{Ag}$. Наличие наночастиц разного типа и размера приводит к появлению мутности из-за локальной разницы показателей поглощения в растворе. Со временем под действием солнечного света происходит расслоение раствора. В осадок выпадают преимущественно частицы $\mathrm{Ag}_{2} \mathrm{~S}$, частицы $\mathrm{Ag}$ формируют зеркальную пленку на поверхности раствора, неагломерировавшие наночастицы, преимущественно $\mathrm{Ag}_{2} \mathrm{~S} / \mathrm{Ag}$, остаются в коллоидном растворе. Воздействие UV-облучения ускоряет процесс агломерации. Отрицательный заряд поверхности ведет к миграции ионов серебра либо из раствора, либо из сульфида серебра. Присоединение ионов $\mathrm{Ag}^{+}$из раствора ведет к укрупнению наночастиц. При достижении размеров 100-200 nm частицы образуют пленку на поверхности раствора или оседают на поверхностях сосудов. При воздействии электронного пучка на агло- мераты высохших частиц $\mathrm{Ag}_{2} \mathrm{~S}$ наблюдается обратимый рост нитей Ag.

При образовании гибридных наночастиц $\mathrm{Ag}_{2} \mathrm{~S} / \mathrm{Ag}$ их взаимодействие приводит к появлению асимметрии в спектре поглощения благодаря резонансному взаимодействию основных носителей металла и полупроводника.

Рассмотрим возможные экситон-плазмонные взаимодействия в наночастице $\mathrm{Ag}_{2} \mathrm{~S} / \mathrm{Ag}$ при фотовозбуждении. Использованное излучение имеет длину волны, при которой оно может поглощаться наночастицами $\mathrm{Ag}_{2} \mathrm{~S}$ и возбуждать поверхностные плазмоны в наночастицах $\mathrm{Ag}$.

Если фотон взаимодействует с металлической наночастицей, то возможны следующие эффекты: 1) рассеяние в дальнюю область; 2) ближнепольное излучение; 3) перенос горячего электрона; 4) плазмонно-резонансный перенос энергии. Рассеяние в дальнюю область и перепоглощение другими частицами может приводить к увеличению общего поглощения раствора. По данным [7] в Ag, где горячие электроны генерируются в основном за счет внутризонных переходов, вероятнее остывание горячего электрона посредством электронфононного взаимодействия и рассеяния тепла в решетку, чем перенос горячего электрона. В соответствии с таким представлением в системе $\mathrm{Ag} / \mathrm{Ag}_{2} \mathrm{~S}$ из безызлучательных процессов наиболее вероятен плазмонно-резонансный перенос энергии (PRET). C другой стороны, по мнению авторов [36], энергия горячих электронов в $\mathrm{Ag}$ может достигать $4 \mathrm{eV}$, и возможен перенос горячих и частично остывших электронов через потенциальный барьер. В наносистеме $\mathrm{Ag} / \mathrm{Ag}_{2} \mathrm{~S}$ при переносе горячих электронов в область границы создается отрицательный заряд интерфейса или поверхности, а следовательно, возникают условия для захвата положительно заряженных ионов из раствора или диффузии ионов серебра из $\mathrm{Ag}_{2} \mathrm{~S}$ к интерфейсу. Это объясняет рост серебряных образований на поверхности $\mathrm{Ag}_{2} \mathrm{~S}$ и/или рост размеров наночастиц.

Поскольку энергия возбуждающего фотона больше ширины запрещенной зоны $\mathrm{Ag}_{2} \mathrm{~S}$, возможно возбуждение и полупроводниковой наночастицы. В этом случае генерируется экситон, возможны безызлучательная рекомбинация, излучательная рекомбинация, перенос энергии от экситона к плазмону. Экспериментально доказана генерация поверхностных плазмонов квантовыми точками на поверхности серебряного нанопровода [2], показана генерация поверхностных плазмонов парой квантовых точек $\mathrm{CdSe} / \mathrm{ZnS}$ в серебряных нанотрубках. При возбуждении наночастицы $\mathrm{Ag}_{2} \mathrm{~S}$ диполь в полупроводнике возбуждает поверхностные плазмоны, т.е. энергия передается за счет ферстеровского резонансного переноса энергии (FRET). Таким образом, в системе металлическая наночастица $\mathrm{Ag}-$ полупроводниковая наночастица $\mathrm{Ag}_{2} \mathrm{~S}$ возможны эффекты FRET и PRET, они конкурируют между собой, но имеют противоположную зависимость от расстояния между полупроводником и металлом. 
В случае прозрачного коллоидного раствора I (через семь месяцев и после облучения) при значительном содержании $\mathrm{Ag}$ и малом $\mathrm{Ag}_{2} \mathrm{~S}$, а также случайном расположении наночастиц относительно друг друга не создаются условия для наблюдения экситон-плазмонного взаимодействия между полупроводниковыми наночастицами $\mathrm{Ag}_{2} \mathrm{~S}$ и металлическим Ag. Укрупнение наночастиц под действием света может происходить благодаря переносу электронов от ионов цитрата к наночастицам Ag.

В случае мутного раствора II присутствие $\mathrm{Ag}_{2} \mathrm{~S}$ и $\mathrm{Ag}$ способствует формированию гетерочастиц $\mathrm{Ag}_{2} \mathrm{~S} / \mathrm{Ag}$. $\mathrm{B}$ них происходит, в частности, FRET от $\mathrm{Ag}_{2} \mathrm{~S}$ к $\mathrm{Ag}$, и экситон-плазмонное взаимодействие проявляется в виде асимметрии пика поглощения системы.

\section{5. Заключение}

Благодаря подвижности ионов $\mathrm{Ag}^{+}$в $\mathrm{Ag}_{2} \mathrm{~S}$ коллоидных растворах сульфида серебра, стабилизированных цитратом, под действием облучения происходит образование металлического серебра на поверхности наночастиц $\mathrm{Ag}_{2} \mathrm{~S}$. В зависимости от времени воздействия, мощности излучения и исходного состояния раствора наблюдается осаждение наночастиц на стенках сосуда, выпадение осадка и образование пленки на поверхности. При образовании гибридных частиц $\mathrm{Ag}_{2} \mathrm{~S} / \mathrm{Ag}$ взаимодействие между экситонами полупроводниковых и плазмонами металлических наночастиц проявляется в локальных изменениях коэффициента поглощения и асимметрии кривой спектра поглощения. Конкретный механизм экситон-плазмонного взаимодействия требует дальнейшего уточнения. Появление отрицательного заряда на поверхности наночастицы $\mathrm{Ag}_{2} \mathrm{~S}$ ведет к протрузии серебра.

\section{Список литературы}

[1] M.L. Brongersma, N.J. Halas, P. Nordlander. Nature Nanotechnol. 10, 25 (2015).

[2] Q. Li, H. Wei, H. Xu. Nano Lett. 14, 3358 (2014).

[3] X.-C. Ma, Y. Dai, L. Yu, B.-B. Huang. Light: Sci. Appl. 5, e16017 (2016).

[4] A.O. Govorov, H.H. Richardson. Nano Today 2, 1, 30 (2007).

[5] E. Khon, A. Mereshchenko, A.N. Tarnovsky, K. Acharya, A. Klinkova, N.N. Hewa-Kasakarage, I. Nemitz, M. Zamkov. Nano Lett. 11, 1792 (2011).

[6] J-Y. Yan, W. Zhang, S. Duan, X.-G. Zhao, A.O. Govorov. Phys. Rev. B 77, 165301 (2008).

[7] W.R. Erwin, H.F. Zarick, E.M. Talbert, R. Bardhan. Energy Environ. Sci. 9, 1577 (2016).

[8] P. Narang, R. Sundararaman, H.A. Atwater. Nanophotonics 5, 1, 96 (2016).

[9] H. Zhang, V. Kulkarni, E. Prodan, P. Nordlander, A.O. Govorov. J. Phys. Chem. C 118, 16035 (2014).

[10] E.-M. Roller, L. Khosravi Khorashad, M. Fedoruk, R. Schreiber, A.O. Govorov, T. Liedl. Nano Lett. 15, 2, 1368 (2015).

[11] T. Bora, D. Zoepfl, J. Dutta. Sci. Rep. 6, 26913 (2016).
[12] J. Yang, N.J. Kramer, K.S. Schramke, L.M. Wheeler, L.V. Besteiro, C.J. Hogan, Jr., A.O, Govorov, U.R. Kortshagen. Nano Lett. 16, 2, 1472 (2016).

[13] G. Zhu, Z. Xu. J. Am. Chem. Soc. 133, 148 (2011).

[14] K. Terabe, T. Nakayama, T. Hasegawa, M. Aono. J. Appl. Phys. 91, 12, 10110 (2002).

[15] L. Motte, J. Urban. J. Phys. Chem. B 109, 46, 21499 (2005).

[16] В.И. Ролдугин. Успехи химии 69, 899 (2000).

[17] N. Satoh, H. Hasegawa, K. Tsujii. J. Phys. Chem. 98, 2143 (1994).

[18] S.I. Sadovnikov, A.I. Gusev, E.Yu. Gerasimov, A.A. Rempel. Chem. Phys. Lett. 642, 17 (2015).

[19] S.I. Sadovnikov, A.I. Gusev, A.A. Rempel. Nano-Struct. NanoObjects 7, 81 (2016).

[20] B.E. Dahneke. Measurement of suspended particles by quasielastic light scattering. Wiley, N.Y., (1983). 570 p.

[21] R. Pecora. Dynamic light scattering: applications of photon correlation spectroscopy. Springer Plenum Press, N.Y., (1985). $420 \mathrm{p}$.

[22] M. Kaszuba., D. McKnight., M.T. Connah, F.C. McNeilWatson, U.J. Nobbmann. Nanopart. Res. 10, 823 (2008).

[23] W. Tscharnuter. In: Encyclopedia of analytical chemistry / Ed. R.A. Meyers. Wiley, N.Y., etc. (2000). P. 5469.

[24] R.J. Hunter. Zeta potential in colloid science: principles and applications. Academic Press, UK (1988). 398 p.

[25] В.В. Кузнецов. Физическая и коллоидная химия. Высш. шк., М. (1968). 390 c.

[26] C. Li, Y. Zhang, M. Wang, Y. Zhang, G. Chen, L. Li, D. Wu, Q. Wang. Biomaterials 35, 393 (2014).

[27] M. Yarema, S. Pichler, M. Sytnyk, R. Seyrkammer, R. Lechner, G. Popovski, D. Jarzab, K. Szendrei, R. Resel, O. Korovyanko, M. Loi, O. Paris, G. Hesser, W. Heiss. ACS Nano 5, 3758 (2011).

[28] W. Zhang, A.O. Govorov, G.W. Bryant. Phys. Rev. Lett. 97, 146804 (2006).

[29] V.G. Rivera, F.A. Ferri, E. Marega, Jr. In: Plasmonics-principles and applications / Eds K.Y. Kim. InTech (2012). Ch. 11.

[30] X.M. Wu, P.L. Redmond, H.T. Liu, Y.H. Chen, M. Steigerwald, L. Brus. J. Am. Chem. Soc. 130, 9500 (2008).

[31] R. Jin, Y.C. Cao, E. Hao, G.S. Métraux, G.C. Schatz, C.A. Mirkin. Nature 425, 487 (2003).

[32] J. Lee, P. Hernandez, J. Lee, A.O. Govorov, N.A. Kotov. Nature Mater. 6, 291 (2007).

[33] A.E. Miroshnichenko, S.V. Mingaleev, S. Flach, Y.S. Kivshar. Phys. Rev. E 71, 036626 (2005).

[34] A.O. Govorov, H. Zhang. J. Phys. Chem. C 119, 6181 (2015).

[35] С.В. Ремпель, Н.Н. Александрова, Ю.В. Кузнецова, Е.Ю. Герасимов. Неорган. материалы 52, 131 (2016).

[36] S. Linic, P. Hristopher, D.B. Ingram. Nature Mater. 10, 911 (2011). 